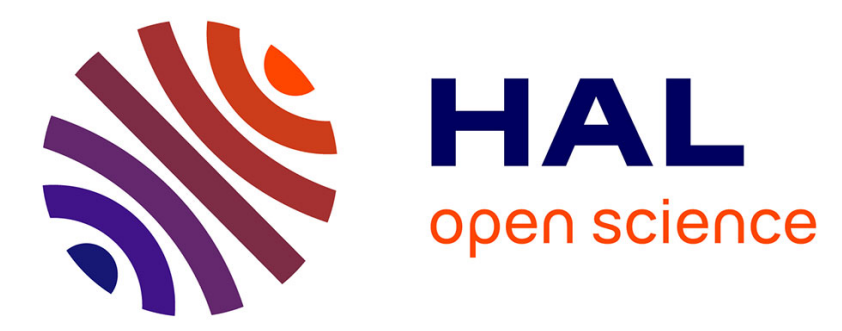

\title{
Regulation and dysregulation of neuronal circuits by KARs
}

\author{
Christophe Mulle, Valérie Crépel
}

\section{To cite this version:}

Christophe Mulle, Valérie Crépel. Regulation and dysregulation of neuronal circuits by KARs. Neuropharmacology, 2021, 197, 10.1016/j.neuropharm.2021.108699 . hal-03432013

\section{HAL Id: hal-03432013 \\ https://hal.science/hal-03432013}

Submitted on 26 Nov 2021

HAL is a multi-disciplinary open access archive for the deposit and dissemination of scientific research documents, whether they are published or not. The documents may come from teaching and research institutions in France or abroad, or from public or private research centers.
L'archive ouverte pluridisciplinaire HAL, est destinée au dépôt et à la diffusion de documents scientifiques de niveau recherche, publiés ou non, émanant des établissements d'enseignement et de recherche français ou étrangers, des laboratoires publics ou privés. 


\title{
Regulation and dysregulation of neuronal circuits by KARs
}

Christophe Mulle $^{1}$ and Valérie Crépel ${ }^{2}$

${ }^{1}$ Univ. Bordeaux, CNRS, Interdisciplinary Institute for Neuroscience, IINS, UMR 5297, F-33000

Bordeaux, France

2 INMED, INSERM UMR1249, Aix-Marseille Université, Marseille, France.

\begin{abstract}
Kainate receptors (KARs) constitute a family of ionotropic glutamate receptors (iGluRs) with distinct physiological roles in synapses and neuronal circuits. Despite structural and biophysical commonalities with the other iGluRs, AMPA receptors and NMDA receptors, their role as post-synaptic receptors involved in shaping EPSCs to transmit signals across synapses is limited to a small number of synapses. On the other hand KARs regulate presynaptic release mechanisms and control ion channels and signaling pathways through non-canonical metabotropic actions. We review how these different KAR-dependent mechanisms concur to regulate the activity and plasticity of neuronal circuits in physiological conditions of activation of KARs by endogenous glutamate (as opposed to pharmacological activation by exogenous agonists). KARs have been implicated in neurological disorders, based on genetic association and on physiopathological studies. A well described example relates to temporal lobe epilepsy for which the aberrant recruitment of KARs at recurrent mossy fiber synapses takes part in epileptogenic neuronal activity. In conclusion, KARs certainly represent an underestimated actor in the regulation of neuronal circuits, and a potential therapeutic target awaiting more selective and efficient genetic tools and/or ligands.
\end{abstract}




\section{Introduction}

Kainate receptors (KARs) are a family of ionotropic glutamate-gated channels (iGluRs) which were molecularly characterized three decades ago (Bettler and Mulle, 1995). Members of the KAR family were cloned (GluK1 to GluK5) and found to form a class of iGluRs closely related to AMPA receptors but distinct in many aspects. KAR subunits can form homomeric glutamate receptors or assemble into heteromeric receptors which are permeable to cations. As a consequence, activation of KAR-gated ion channels leads to neuronal depolarization. KAR subunits form a distinct class as they do not coassemble with AMPA and NMDA receptor subunits. KARs are widely distributed throughout the brain and serve a variety of roles in synaptic transmission and plasticity, in the maturation of neuronal circuits and in the regulation of neuronal excitability (Contractor et al., 2011; Lerma and Marques, 2013) (see other reviews in this issue of Neuropharrmacology).

The present review attempts to bring together knowledge on the role played by KARs in the control of activity of neuronal circuits. We choose to focus on conditions in which KARs are activated by endogenously released glutamate, not by pharmacological activation. Activation of KARs by externally applied agonists have robust effects, and the wealth of earlier studies have certainly been instrumental in highlighting rather wide-spread expression of functional KARs and the diversity of roles they could play. However, because of the artificial conditions of activation of KARs in terms of timing and local concentrations of the agonists at specific locations within neuronal circuits, these pharmacological actions have not been sufficient to get a full understanding of the neurophysiological role of KARs.

Unlike AMPA and NMDA receptors, localization of KARs to postsynaptic densities is not ubiquitous in all neurons throughout the CNS, although a large majority of neuronal populations express one or the other of the KAR subunits. As exemplified below, KARs can function as bona fide postsynaptic ionotropic receptors participating in the EPSC, however this may not be their most widespread mode of action. KARs also participate in the regulation of neurotransmitter release and in presynaptic forms of short-term plasticity, although the mechanism of action is still mostly unclear (Pinheiro and Mulle, 2008). Moreover, in many instances KARs act through a non-canonical (non-ionotropic) mode of action through activation of second messenger signaling pathways (Valbuena and Lerma, 2016). How these different modes of actions of KARs participate in the control of synaptic circuits and information processing in the brain and in the activity of neuronal ensembles in relation to behaviour, in physiological and disease-related conditions, remain exciting and rather open questions in the field.

What are the tools at hands for exploring the roles of KARs? The paucity of pharmacological agents to selectively block KARs while sparing AMPARs and NMDARs (Contractor et al., 2011) has hampered efficient testing of the impact of endogenous KAR activation on the activity of neuronal circuits. Substantial efforts have however been made to develop KAR selective antagonists following cloning of the KAR subunits (Jane et al., 2009). Most of the compounds developed with good selectivity over AMPARs currently target GluK1 containing KARs including UBP 304 and UBP310 (Dolman et al., 2007) which have been used to block KAR function in vivo and in vitro (Jane et al., 2009). We are in general lacking highly selective antagonists targeting the most abundant KAR isoform GluK2/GluK5, albeit UBP310 was also found to block synaptic receptors comprising GluK2/GluK5 KARs in vitro and in vivo (Pinheiro et al., 2013). Recently however quinoxaline-2,3-dione analogues have been synthetized and shown to have a good pharmacological selectivity at GluK3 over GluK1 and AMPARs (Møllerud 
et al., 2019). This may offer possibilities in the future to better understand the physiological role of the elusive Gluk3 subunit.

Knock-out mice for each of the KAR subunits have been instrumental in identifying KARs involved in the various functions of KARs in synaptic circuits and in relation to behaviour (Contractor et al., 2011). It should be kept in mind however, that because of the clearcut implication of KARs during development (ref Sari Lauri's review in this issue of Neuropharmacology), it is likely that part of the phenotypes observed in KAR subunit knockout mice at the synaptic, circuit and systems level may arise from alteration of maturation of synaptic circuits. Conditional knock-out mice for the different KAR subunits counteract this limitation and their use will address the impact of cell-specific removal of KAR subunits at the adult stage (Marshall et al., 2018).

\section{KAR-EPSCs and integration of synaptic signals}

Hippocampus. Hippocampal mossy fiber synapses onto CA3 pyramidal cells (Mf-CA3 synapses) stand apart in the study of KARs as these cells and synapses were the first in which a physiological role of KARs activated by endogenously released glutamate was described (Castillo et al., 1997; Vignes and Collingridge, 1997). Since then Mf-CA3 synapses have continued to be a much favoured model for the study of KARs, from the cell biological mechanisms of synaptic recruitment and stabilization to their physiological role in synaptic transmission and plasticity (Figure 1), as well as during synaptic maturation (reviewed in Carta et al., 2014; Lerma and Marques, 2013). A single presynaptic stimulation is sufficient to activate postsynaptic KARs which can be revealed in the presence of GYKI 53655 (LY307070) to block AMPA receptors (Castillo et al., 1997). Surprisingly, KARs comprise only a small component of the postsynaptic response, accounting for less than $10 \%$ of the amplitude of Mf-CA3 EPSCs (Marchal and Mulle, 2004). The use of KAR subunit ko mice has identified GluK2 as the main subunit comprising synaptic KARs at Mf-CA3 synapses (Mulle et al., 1998). However, KARs activated by synaptic release of glutamate at Mf-CA3 synapses are heteromeric receptors combining GluK2, GluK4 and GluK5, as KAR-EPSCs are absent in the double GluK4/GluK5 ko mice (Fernandes et al., 2009). The stoichimetry of these heteromeric receptors is unknown, although there is yet no evidence for the presence of homomeric GluK2-KARs (Fievre et al., 2016), and GluK4 appears essential for the recruitment of synaptic KARs at Mf-CA3 synapses as it is the target of transsynaptic regulation by the C1ql2/3 proteins (Matsuda et al., 2016). In CA3 pyramidal cells, KARs are highly compartmentalized at Mf-CA3 synapses and are absent at other synapses or in extrasynaptic compartments (Fievre et al., 2016). Similarly, in hilar mossy cells, KAR-EPSCs are present at Mf inputs, but absent at inputs from CA3 pyramidal cells (Hedrick et al., 2017).

Bath application of KAR agonists activates inward currents in CA1 pyramidal cells (Bureau et al., 1999) and DG granule cells (Valérie Crépel - unpublished observations) indicating the presence of somato-dendritic KARs, in line with the expression of GluK2 and GluK5 in these neurons (Bureau et al., 1999). However synaptically released glutamate does not activate KAREPSCs in these neuronal populations (Bureau et al., 1999; Epsztein et al., 2005). KAR-EPSCs with low amplitude and slow decay kinetics were recorded in CA1 interneurons in the rat (Cossart et al., 1998; Frerking et al., 1998; Frerking and Ohliger-Frerking, 2002; Yang et al., 2007), although this has not been reported in the mouse. KARs in hippocampal interneurons likely comprise both GluK1 and GluK2 (Mulle et al., 2000). 


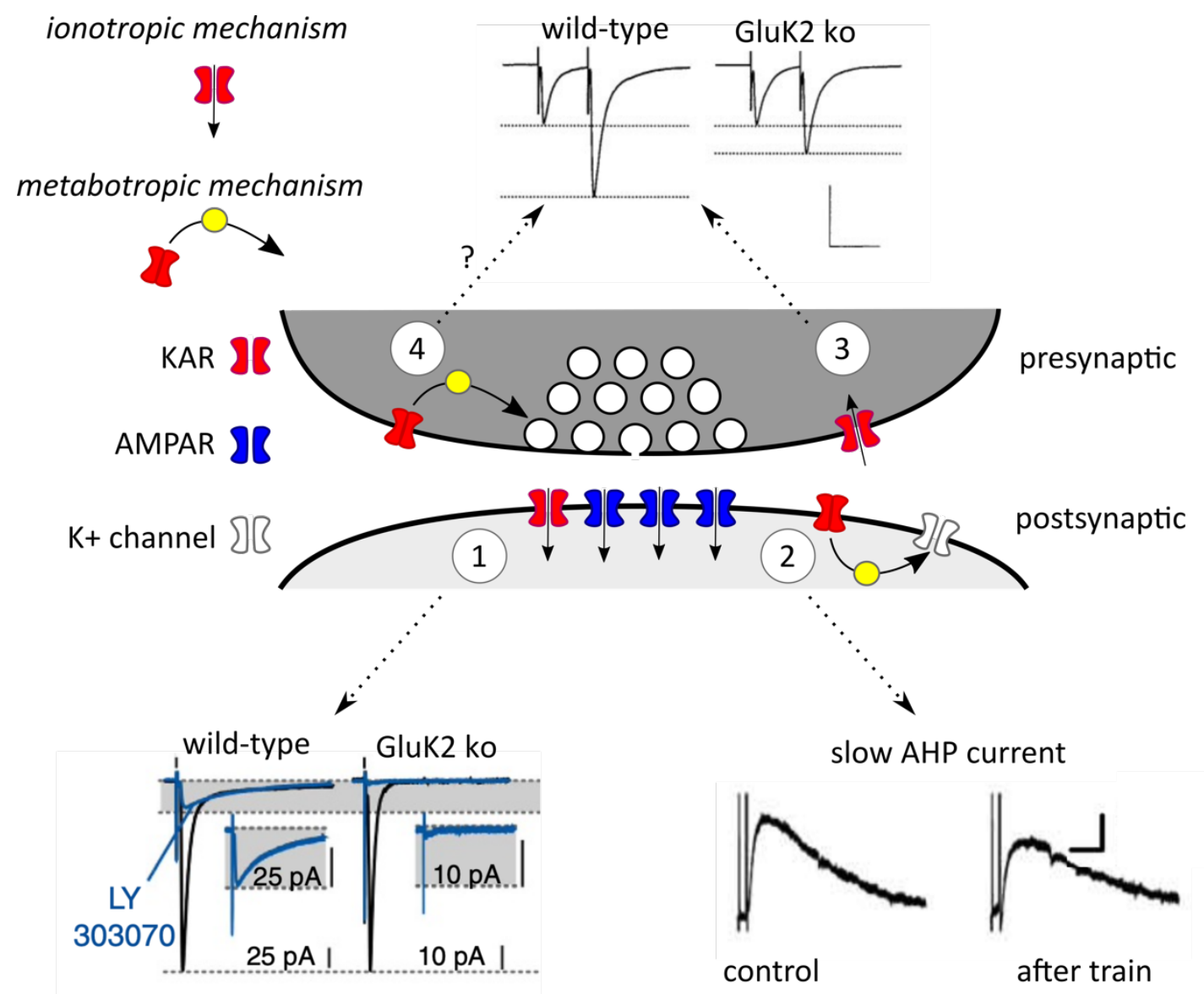

Figure 1 - Schematic illustration of the different modes of action of KARs at Mf-CA3 synapses at pre- and postsynaptic sites, and through both ionotropic and metabotropic mechanisms. Experimental data shown are adapted from Contractor et al, 2001, Fièvre et al, 2016 and Ruiz et al, 2005.

The slow decay kinetics of KAR-EPSCs appears to be a key feature which differentiates synaptic KARs from AMPARs. The slow kinetics is likely multifactorial, but seems to depend on the biophysical properties of GluK2/GluK5 (Barberis et al., 2008) and interaction with the auxilliary proteins Neto1 and Neto2 (Copits and Swanson, 2012; Straub et al., 2011; Tang et al., 2011). An interesting study combining slice electrophysiology and modeling has provided several indications as to the relative impact of ionotropic mechanisms through KARs vs. AMPARs in hippocampal interneurons (Frerking and Ohliger-Frerking, 2002). First, because of their slow kinetics, KAR-EPSCs are likely to have a larger impact on membrane depolarization (KAREPSPs) than AMPAR-EPSCs relative to their amplitude. Second, with repetitive presynaptic stimulation above $3 \mathrm{~Hz}$, synaptic activation of KARs leads to a tonic depolarization that is larger and much less variable than with AMPARs (Frerking and Ohliger-Frerking, 2002). Overall, it is proposed that the different modes of depolarization may encode distinct aspects of afferent activity, with variable and large transient depolarization mediated by AMPARs, and KARs leading to a larger and more regular depolarization less sensitive to the temporality of firing in the afferent input (Frerking and Ohliger-Frerking, 2002).

Only a few studies have directly investigated the role of post-synaptic KARs in synaptic integration and information transfer within hippocampal circuits. Of several possible reasons, disentangling the different possible actions of KARs would require selective removal from prevs postsynaptic sites. The finding that UBP310 efficiently blocks the ionotropic action of postsynaptic KARs-EPSCs without affecting their non-canonical metabotropic action, nor presynaptic KARs, has allowed to directly test the impact of KARs in information transfer at 
Mf-CA3 synapses (Pinheiro et al., 2013). The blockade of KAR-EPSCs at Mf-CA3 synapses reduces the sustained depolarization which builds up during repetitive activity of presynaptic DG afferents, and impacts on spike transmission mediated by heterosynaptic signals (Pinheiro et al., 2013). Interestingly CA3 pyramidal cells in GluK5 ko mice, in which the decay kinetic of KAR-EPSCs is accelerated (Contractor et al., 2003), display reduced firing in response to short bursts of presynaptic stimulation (Sachidhanandam et al., 2009). Overall, these results indicate that KAR-EPSCs, although displaying low amplitude relative to AMPAR-EPSCs, play a role in synaptic integration and spike transfer due to their slow decay kinetics which allows substantial tonic depolarization in conditions of repetitive firing of presynaptic afferents or coactive inputs.

Similarly KARs are hypothesized to have a substantial effect on the membrane potential of GABAergic interneurons during afferent activity similar to that measured in vivo. This has been documented at excitatory synapses onto interneurons in the hippocampus. Electrophysiological recordings from somatostatin-positive neurons in the stratum orienslacunosum moleculare (O-LM cells) revealed the crucial contribution of synaptic KARs to the firing activity (Yang et al., 2007) and to the sustained response to theta stimulation of excitatory afferrents (Goldin et al., 2007). However the study provided some evidence that the EPSP kinetics alone cannot account for the ability of the O-LM cells to reliably follow theta stimulation and that a specific interaction between synaptic KARs and the active membrane properties specific to this particular cell type could play a role (Goldin et al., 2007). A selective GluK1 antagonist (UBP304) was administered in vivo to block the activity of KARs, while performing EEG and single-unit recordings from the dorsal hippocampus of awake, freely moving rats trained to forage for food (Huxter et al., 2007). This pharmacological approach targets KARs in GABAergic interneurons, since GluK1 is selectively expressed in these neurons in the hippocampus (Mulle et al., 2000; Paternain et al., 2000). UBP304 lowered the frequency of theta modulation of hippocampal interneuron discharge, and in parallel reduced the firing rates and the precision of firing within place fields (Huxter et al., 2007). These parallel studies provide evidence for a link between postsynaptic KARs in hippocampal interneurons and theta oscillations, albeit more selective genetic tools targeting KARs in hippocampal interneurons would be required to confirm the link between postsynaptic KARs and theta oscillations, and their possible role in spatial information processing and memory encoding.

Neocortex. All KAR subunits are highly expressed in the neocortex, and KAR currents activated by exogenous KAR agonists have been recorded in various neocortical areas and cell types (Zhuo, 2017a). However, as in the hippocampus, the excitatory synaptic inputs in which KAREPSCs have been recorded are scarce. KARs in the entorhinal cortex (EC) have received some attention likely because of a postulated role of KARs in rythmogenicity and in epileptogenesis (Cunningham et al., 2003). KAR-EPSCs can be evoked in EC LIII pyramidal neurons (and to a lesser extent in LII neurons), in a pathway specific manner (Beed et al., 2009; Chamberlain et al., 2011; West et al., 2007). KAR-EPSCs have also been recorded in the superficial layers of the anterior cingulate cortex (Wu et al., 2005), the insular cortex (Koga et al., 2012) and the motor cortex (Ali, 2003). In all these studies, KAR-EPSCs have relatively small amplitudes (less than $20 \%$ of the AMPAR component) and display decay kinetics far slower than that of the AMPAR-EPSCs (however see (Eder et al., 2003).

Other brain regions. EPSCs mediated by KARs have also been recorded in the basolateral amygdala (H. Li and Rogawski, 1998), in the dorsal horn of the spinal cord (P. Li et al., 1999), in the Golgi cells of the cerebellum (Bureau et al., 2000), and in the retina at synapses between 
between cones and 'Off' bipolar cells (DeVries and Schwartz, 1999). KAR-EPSCs have failed to be detected in many neuronal types which express KAR subunits, and for which somatodendritic KARs can be activated by the exogenous application of an agonist, as for instance in CA1 pyramidal cells (Bureau et al., 1999). Albeit, in striatal medium spiny neurons high frequency stimulation of cortical afferents engage post-synaptic GluK2 KARs to inhibit synaptic transmission through the release of endocannabinoids (Marshall et al., 2018). This indicates that postsynaptic KARs may be activated in response to trains of afferent stimulation, although a conventional EPSC is hardly detected or very small (Xu et al., 2017) (see also (Melyan et al., 2004; Petrovic et al., 2017)). Another striking feature of synaptic KARs, is their compartmentalized expression at selective inputs on a given neurons (Fievre et al., 2016). As an example in the basolateral amygdala, synaptic responses mediated by GluK1containing KARs are observed at inputs from the external capsule but not from the basal amygdala (H. Li and Rogawski, 1998); in the dorsal horn KARs contribute to sensory synaptic transmission activated by high-threshold nociceptive fibers but not low threshold fibers (P. Li et al., 1999). Finally KARs and AMPARs are generally co-expressed at posysnaptic sites, with a low relative amplitude of KAR-EPSCs. Synapses between between cones and 'Off' bipolar cells constitute an exception in which pure KAR-EPSCs exist (DeVries and Schwartz, 1999).

The slow decay kinetics and summation of KAR-EPSCs in response to repeated stimulation appears as a general rule. As in CA3 pyramidal cells and in O-LM interneurons, this suggests a role for postsynaptic KARs in synaptic integration and efficacy of spike transfer, although experiments exploring the role of KARs at all these other synapses remain scarce.

\section{Presynaptic mechanisms}

Ionotropic glutamate receptors are predominantly expressed postsynaptically, albeit they have also been found presynaptically to regulate neurotransmitter release and presynaptic forms of synaptic plasticity (Pinheiro and Mulle, 2008). A presynaptic function of KARs has long been suggested based on the effects of exogenous KAR agonists on synaptic release mechanisms (e.g see (Rodriguez-Moreno et al., 1997)). Here we will only consider presynaptic mechanisms involving activation of KARs in physiological conditions by the endogenous agonist, as studied with either KAR antagonists or genetic invalidation of KAR subunits.

The strongest evidence for a role of KARs in presynaptic function stems from work on Mf-CA3 synapses (Contractor et al., 2001; Lauri et al., 2001; Pinheiro et al., 2007; Schmitz et al., 2001). The facilitatory action of presynaptic KARs is fast $(<10 \mathrm{~ms})$ indicating that they can be activated as autoreceptors by synaptically released glutamate (Kamiya et al., 2002; Schmitz et al., 2001). Presynaptic KARs strongly contribute to short- and long term presynaptic facilitation, which are key features of Mf-CA3 synapses. Studies in ko mice indicate that GluK2 and GluK3 are the main KAR subunits involved in presynaptic facilitation at Mf-CA3 synapses (Contractor et al., 2001; Pinheiro et al., 2007). The mechanism of action is yet somewhat unclear; it likely involves increased $\mathrm{Ca}^{2+}$ influx in presynaptic terminals (Kamiya et al., 2002; Scott et al., 2008a), but KARs may also exert at least part of their action through a depolarization of the mossy fiber bouton that does not involve changes in $\mathrm{Ca}^{2+}$ (Scott et al., 2008b). Importantly presynaptic KARs strongly favor spike transmission in response to patterns of presynaptic activity mimicking in vivo dentate granule cell activity, and are thus thought to act as conditional amplifiers of synaptic transmission (Sachidhanandam et al., 2009).

Excitatory synapses onto somatostatin (SOM) interneurons display robust frequency facilitation which depends on $\mathrm{Ca}^{2+}$ permeable presynaptic KARs in CA1 (Sun et al., 2009; Sun 
and Dobrunz, 2006; Sylwestrak and Ghosh, 2012). Pharmacological studies using NS102 suggest that presynaptic KARs also participate in the facilitation of inputs onto L2/3 SOM interneurons in the sensory cortex, but not in L5 (Stachniak et al., 2019). The activity of presynaptic KARs in response to high frequency trains of stimuli thus enhance the recruitment of SOM interneurons, as evidenced by the reduced number of stimuli required for spiking of these neurons as compared to L5 SOM neurons (Stachniak et al., 2019). Presynaptic KARs present in GABAergic terminals, activated by ambiant or synaptically released glutamate, participate in heterosynaptic regulation of the inhibitory tone in several brain regions (Braga et al., 2003; Daw et al., 2010; Jiang et al., 2001; Kerchner et al., 2001; Lourenço et al., 2010; Wyeth et al., 2017). Blockade of KARs decreases GABAergic synaptic transmission in paired recordings of interneurons and pyramidal cells in CA1, indicating that basal glutamate in the slice is sufficient to positively regulate presynaptic GABA release (Jiang et al., 2001). Interestingly, stimulation of the excitatory stratum radiatum fibers potentiates unitary IPSCS by glutamate activation of presynaptic KARs, which may function as a negative feedback control in local circuits (Jiang et al., 2001). A further study showed that facilitation of GABAergic transmission by stimulation of the Schaffer collaterals is observed at connections expressing presynaptic GluK1 receptors, but not the endocannobinoid CB1 receptors (Lourenço et al., 2010). In fact, in interneurons of the CCK/CB1 type, KARs induce a reduction in evoked IPSCs (Daw et al., 2010; Lourenço et al., 2010). The depression which can be observed with synaptically released glutamate to activate KARs appears to rely on an enhancement of the activity of CB1 receptors produced by mGluR-dependent release of endocannabinoids (Lourenço et al., 2010). Further supporting the inhibitory action of presynaptic GluK1-KARs in terminals of CCK/CB1 expressing interneurons, tonic suppression of inhibition is lost in mice knock-out for the Neto subunits (Wyeth et al., 2017). Similarly, in the pyramidal cells of the basolateral amygdala, pharmacological administration of LY293558 decreases failures of evoked IPSCs, indicating that basal levels of extracellular glutamate escaping from excitatory synapses tonically inhibit the activity of nearby inhibitory synapses via presynaptic GluK1 kainate receptors (Braga et al., 2003). In summary, presynaptic GluK1 KARs activated by basal levels of ambiant glutamate appear to either inhibit or enhance GABA release depending of the type of interneurons, and this regulation of inhibition may be favoured in conditions of increased activity of excitatory afferents. What the net effect is in terms of circuit activity, depends on the actual levels of glutamate in the extracellular space in vivo. Synaptically-released glutamate from primary afferent sensory fibers was also shown to reduce inhibition in the dorsal horn of the spinal cord (Kerchner et al., 2001), possibly facilitating the relay of sensory information to higher brain centers (Zhuo, 2017b).

A tonic action of presynaptic KARs has also been described during maturation in principal cells. In the immature hippocampus, application of the GluK1 antagonist LY382884 reversibly increases evoked EPSC amplitude at CA3-CA1 synapses, indicating that inhibitory presynaptic KARs are tonically activated by ambiant glutamate (Lauri et al., 2005; 2006). This GluK1dependent inhibitory control of excitatory synapses is downregulated during postnatal maturation, and can be rapidly switched off in response to a high frequency LTP protocol (Lauri et al., 2006). By tonically inhibiting release probability, presynaptic KARs sets the dynamic properties of neonatal inputs in favor of synaptic facilitation during high frequency bursts of incoming activity, typical for developing neuronal networks (Lauri et al., 2006). The molecular mechanisms and complex interplay between plasticity and regulation of KARs in immature circuits has been reviewed recently (Lauri et al., 2021).. 
Besides its role in the modulation of ongoing neuronal activity, presynaptic KARs participate in some forms of synaptic plasticity. This has been observed for presynaptic forms of longterm potentiation (LTP) at Mf-CA3 synapses using KAR antagonists (Lauri et al., 2001) or KAR subunit ko mice (Contractor et al., 2001; Pinheiro et al., 2007). The mechanism involved has not been clearly defined, but may simply derive from the role of KARs in short-term facilitation during the bursts of stimulation, hence strengthening the induction of LTP. Activation of presynaptic KARs also promotes presynaptic LTP at thalamic inputs to the lateral amygdala (Shin et al., 2010), and possibly in the anterior cingulate cortex (ACC) (Koga et al., 2015). Interestingly, presynaptic KARs appear necessary for presynaptic LTD induced by low frequency stimulation of parallel fiber to Purkinje cell synapses, paired with depolarization of Purkinje cells (F. Crépel, 2009).

\section{Metabotropic actions of KARs}

In addition to their canonical ionotropic function, KARs also activate non-canonical pathways, which have been extensively studied and characterized in response to their activation by externally applied agonists (Valbuena and Lerma, 2016). Here we review the evidence for noncanonical actions of KARs activated by endogenously released glutamate, and their impact on the regulation of neuronal circuits. Amongst the apparent multiplicity of mechanisms proposed for the regulation of neurotransmmitter release by presynaptic KARs, some are thought to involve a non-canonical action of KARs (Pinheiro and Mulle, 2008; Valbuena and Lerma, 2016). Direct evidence for non-canonical mechanisms in physiological conditions of activation of presynaptic KARs is however scarce. The interaction of presynaptic KARs and the endocanabinoid system to inhibit GABA release is one such example (Lourenço et al., 2010), although the precise mechanism remains to be defined.

There are however strong evidence that KARs activated by synaptically released glutamate regulate the activity of ion channels (Melyan et al., 2004). Activation of KARs by a short bursts of stimulation of Schaffer collaterals control the excitability of CA1 pyramidal cells via modulation of a slow afterhyperpolarization (SAHP) (Melyan et al., 2004). The regulation of SAHP by KARs requires a metabotropic cascade which depends on PKC activation (Melyan et al., 2004). It is interesting to point out that synaptically released glutamate which controls SAHP through KARs, does not trigger KAR-mediated EPSCs in CA1 pyramidal cells (Melyan et al., 2004), although functional KARs are present in the dendritic compartment (Bureau et al., 1999). Postsynaptic KARs with a metabotropic action were further found to trigger a form of LTP in CA1 pyramidal cells in response to a train of high frequency stimulation of excitatory afferents (Petrovic et al., 2017). Synaptic activation of postsynaptic KARs reversibly inhibits a sAHP at Mf-CA3 synapses through a metabotropic action that requires the GluK5 subunit (in addition to the obligatory GluK2 subunit) (Ruiz et al., 2005)(note that the involvement of GluK5 was not confirmed by Fernandes et al, 2009, for reasons which remain unclear). Unlike KAR-EPSCs which can be evoked by a single presynaptic action potential, inhibition of sAHP through KARs requires an extended train of presynaptic stimulation (Ruiz et al., 2005). As a consequence, synaptic activation of GluK2/GluK5 KARs increases spike transmission between the DG and CA3 in response to trains of presynaptic stimulation by controlling the excitability of postsynaptic pyramidal cells (Sachidhanandam et al., 2009). Postsynaptic KARs at Mf-CA3 synapses are subject to LTD (Carta et al., 2013; Chamberlain et al., 2013; Selak et al., 2009). Interestingly, in the piriform cortex, trains of synaptic stimulation results in long-lasting enhancement of neuronal excitability in neurons from controls through activation of KARs, but not in animals which have learned a complex olfactory task (Chandra et al., 2019). Overall 
postsynaptic KARs appear to promote spike transmission at a subset of excitatory synapses in the hippocampus and in the cortex in conditions of repetitive input stimulation both through ionotropic and metabotropic mechanisms.

In the immature hippocampus, the spiking activity of CA3 interneurons is maintained at a high level through the metabotropic regulation of mAHP by GluK1-KARs activated by tonic glutamate (Segerstråle et al., 2010). In mice, KAR-dependent regulation of excitability disappears by the end of the second postnatal week because of a developmental decoupling between KAR activation and mAHP inhibition (Segerstråle et al., 2010). In immature neuronal circuits, the tonic suppression of glutamate release by Gluk1-containing receptors is also proposed to relie on a metabotropic action of KARs (Lauri et al., 2006).

\section{Integrative circuit mechanisms}

In view of the multiplicity of roles that KARs can play in neuronal circuits through actions on membrane potential, on synaptic release of glutamate and GABA and on the regulation of ion channels (Figure 2), an integrative view of the impact of KARs is awaited. This has proven not be an easy task, in part due to the lack of a selective antagonist of KARs which would span all subtypes. A full knock-out of all five KAR subunits has been generated, and mainly studied within the context of cortico-striatal function for which a major phenotype is observed (Xu et al., 2017). In studying dysfunction of neuronal circuits in constitutive KAR-subunit ko mice it is important to take into consideration the role that KARs during postnatal development (Lanore et al., 2012; Lauri et al., 2006; Segerstråle et al., 2010), as well as potential homeostatic compensatory mechanisms. This likely limits the possibility from obtaining a clear integrative view of the function of KARs in the regulation of mature circuits. The availability of conditional ko mice (e.g for GluK2, (Marshall et al., 2018)) will certainly allow to circumvent at least in part these issues.
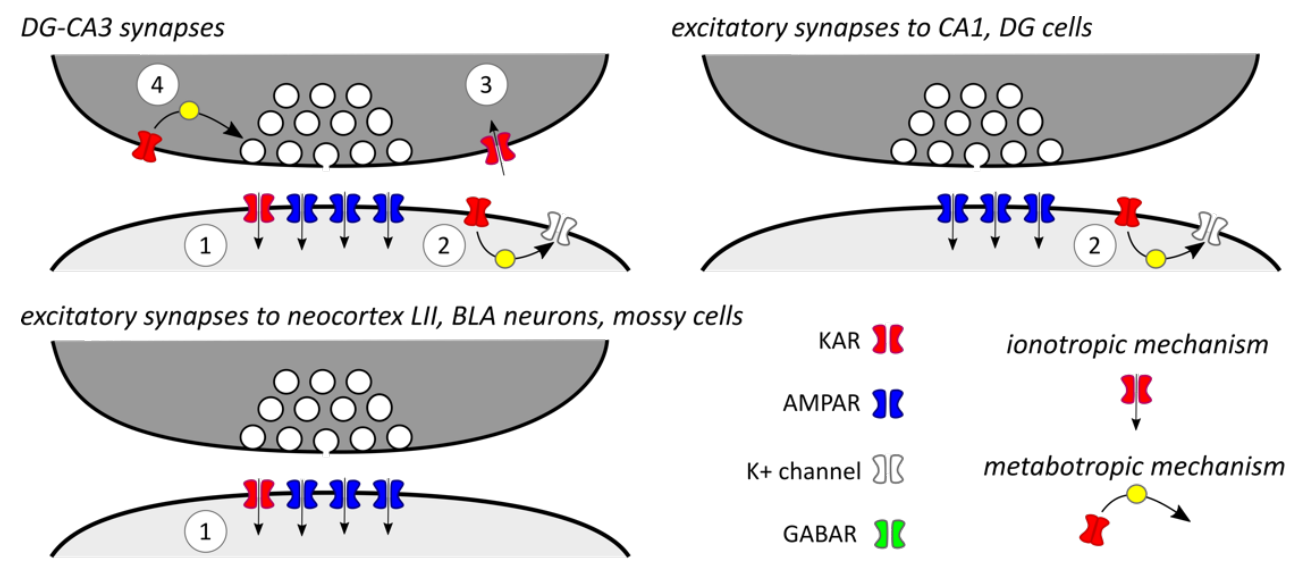

excitatory synapses onto interneurons (SOM)

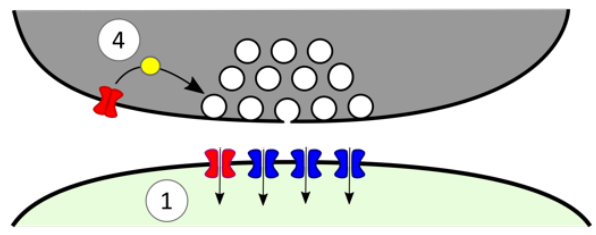

inhibitory synapses onto interneurons (CCK)

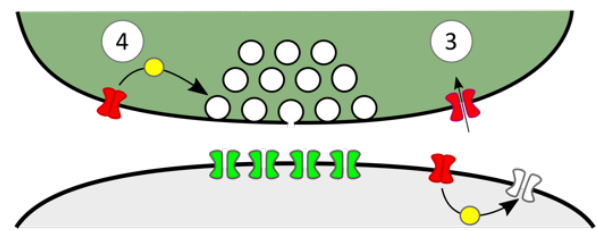

Figure 2 - Schematic illustration of the diverse role of KARs which vary amongst synapses and neuronal types.

Based on pharmacological approaches mainly using kainate as an agonist, a number of studies have involved KARs in rythmogenesis in the hippocampus (Fisahn et al., 2004; Huxter et al., 2007) and in the entorhinal cortex (EC) (Beed et al., 2009; Chamberlain et al., 2011; Cunningham et al., 2003; 2006a). The role played by KARs in physiologically occuring 
oscillations has been much less characterized. A single study has tested the impact of available pharmacological agents against KARs on neuronal circuit activity in vivo (Huxter et al., 2007). EEG and single units recordings were made from the dorsal hippocampus of rats foraging for food, which received administration of UBP304, developed as a GluK1 antagonist (Huxter et al., 2007). This study showed that blocking KARs reduced the frequency, but not the power, of theta oscillations, and induced a degradation in the coherence of spatial firing patterns in place cells (Huxter et al., 2007). Because of the selective expression of GluK1 in GABAergic interneurons, inhibition of KARs by UBP304 possibly affects the activity of pacemaker interneurons which entrain hippocampal pyramidal cells during theta oscillations.

Slow wave oscillations, which are particularly manifest during periods of behavioral quiescence and are critical for learning and memory (Steriade, 1993), can be recorded in EC slices (Cunningham et al., 2006b). UBP302, abolished the up phase of slow wave sleep at both the single-cell and population level, and this was correlated with faster-decaying spontaneous EPSPs recorded in LIII pyramidal neurons (Cunningham et al., 2006b). This brings further demonstration for the importance of the slow decay time of KAR-EPSPs in shaping the activity of neuronal circuits. As indicated above, UBP302 was designed as a GluK1 antagonist, but was later shown to block GluK2/GluK5 KARs, in line with the occurrence of GluK2-containing synaptic KARs in LIII pyramidal neurons (Beed et al., 2009).

\section{KARs in the pathological dysregulation of neuronal circuits}

The best evidence for a role of KARs in the pathological dysfunction of neuronal circuits comes from experiments in chronic models of temporal lobe epilepsy (TLE). In both human patients and animal models of TLE, it is well established that glutamatergic fibers sprout and establish novel synapses leading to pathological glutamatergic excitatory networks and seizure activities (Noebels et al., 2012; Represa et al., 1989; Sutula et al., 1989). The sprouted axons, observed in the dentate inner molecular layer, mostly originates from immature dentate granule cells (2-4 weeks old at the time of status epilepticus) (Kron et al., 2010). In animal models of TLE the sprouted mossy fibers making synapses onto DG cells are endowed with a KAR-mediated synaptic component absent in DG cells from naïve animals (Epsztein et al., 2005). In DG cells of chronic TLE rats, stimulation of excitatory afferents in the inner molecular layer trigger KAR-EPSCs that provides as much as half of the total glutamatergic synaptic tone (Epsztein et al., 2005). Mossy fibers induce the recruitment of GluK2-containing KARs in DG granule cells likely through similar mechanisms (involving the C1q-like proteins C1ql2 and C1ql3) as in CA3 pyramidal cells (Matsuda et al., 2016).KAR-EPSCs generated in DG granule cells in chronic TLE rats share common physiological features with KARs at Mf-CA3 synapses (V. Crépel and Mulle, 2015); they display a slow time course of decay when compared with AMPAR-EPSCs (Epsztein et al., 2005) a key feature supporting temporal summation and spike transmission. Ectopic KAR-EPSCs at sprouted Mf synapses shift the sparse firing of DG granule cells to a sustained firing mode (Artinian et al., 2011) resembling the "detonator" feature described in CA3 pyramidal cells (Sachidhanandam et al., 2009). Interestingly, the sustained and aberrant firing driven by KARs also trigger a long-lasting disruption of the perforant path input-output operation in epileptic DG cells (Artinian et al., 2015). This is due to the activitydependent potentiation of a persistent sodium current, which results in anomalous longlasting increase of intrinsic hyperexcitability of "epileptic" DG cells (Artinian et al., 2015). Therefore, the impact of ectopic KARs in the physiopathology of "epileptic" DG cells is not only restricted to an aberrant readout of synaptic inputs by KARs but also interfere with the temporality of firing of these cells due to the long lasting change in their intrinsic properties. 
It was further shown that blocking aberrant KAR-EPSCS with UBP310 or genetic ablation of GluK2 drastically reduces the number of seizures in TLE mice supporting the notion that GluK2/GluK5 play a key role in seizure generation in TLE (Peret et al., 2014). This finding was further confirmed in $\mathrm{C} 1 \mathrm{ql} / 2 / 3$ null mice in which the post-synaptic recruitment of ectopic GluK2/GluK5 KARs at recurrent Mf-DG cell synapses is prevented (Matsuda et al., 2016). The contribution of KARs to chronic seizures in human TLE is yet unknown, albeit Mf sprouting is a key histopathological features of the disease. If fact it is anticipated that the human DG is endowed with aberrant KARs in patients with TLE, since increased high affinity kainate binding was observed in the inner molecular layer of the DG (Represa et al., 1989).

The grik4 gene encoding GluK4 maps to the 11q23.3-q24.1 locus in human, which is duplicated de novo in autism and intellectual disability, and mice overexpressing grik4 in the forebrain display social impairment, enhanced anxiety, and depressive states (Aller et al., 2015; Arora et al., 2018). A mild gain in GluK4 in this mouse model is sufficient to create an imbalance between the inhibitory and excitatory activity in amygdala output neurons (Arora et al., 2018), mainly due to the tonic activation by presynaptic KARs. It is proposed that the consequent hyperexcitability of basolateral amygdala output neurons in the mouse model of grik4 gene duplication is associated with increased anxiety-like behaviors (Arora et al., 2018). Further genetic studies indicate that mutations in grik2 and grik4 affecting KAR function confer risk for neurodevelopmental disorders (Guzmán et al., 2017; Koromina et al., 2019), awaiting evidence that these variations impact on the activity of neural circuits.

Recent observations have shown that GluK2-containing KARs are also upregulated in autosomal recessive juvenile parkinsonism, a neurodegenerative disease characterized by dysfunction and death of dopamine neurons in the substantia nigra pars compacta. The disease is causally related to loss-of-function mutations in the PARK2 gene; PARK2 encodes the protein parkin which interacts with GluK2 (Maraschi et al., 2019). In the absence of parkin, GluK2 is upregulated in human tissues from patients with autosomal recessive juvenile parkinsonism and in mouse models of the disease (Maraschi et al., 2019; Regoni et al., 2020). In the parkin Q311X mouse, a model of human parkin-induced toxicity, chronic administration of UBP310 not only reduces the loss of dopaminergic neurons, but also rescues the abnormal firing rate of nigral dopaminergic neurons (Regoni et al., 2020). KAR function in DA neurons is still unexplored, however this recent study supports a role for endogenous activation of GluK2 in the chronic and abnormal upregulation of spontaneous firing in these neurons.

\section{Conclusions}

Although KARs are widely expressed in the brain and were shown to exert multiple functions in synaptic transmission and plasticity, a comprehensive overview of their role in the control of the activity of neuronal circuits in relation to brain states and behaviour is only progressing slowly. As mentioned, highly selective, and possibly KAR subunit-specific, antagonists and/or genetic tools are mostly lacking. Their use in combination with state-of-the art electrophysiological recordings (or $2 \mathrm{P}$ cellular calcium imaging) in vivo, in awake behaving animals would certainly resolve uncertainties as to the integrative function of KARs in the brain. Conditional knock-out mice for the KAR subunits (Marshall et al., 2018) should hold promise not only in circumventing the involvement of KARs during maturation of neuronal circuits, but also in clarifying their role in a selected neuronal population or brain region, spanning from synapses to circuits and related behaviours.

\section{Acknowledgements:}


CM and VC's work is supported by the Institut National de la Santé et de la Recherche Médicale (INSERM to VC), the Centre National de la Recherche Scientifique (CNRS to CM), Aix-Marseille Université (AMU to VC), and the Agence Nationale de la Recherche (ANR, ANR-17-NEU3-000302, ANR-18-CE17-0023-01 to CM and VC). 


\section{Bibliography}

Ali, A.B., 2003. Involvement of post-synaptic kainate receptors during synaptic transmission between unitary connections in rat neocortex. Eur J Neurosci 17, 2344-2350. doi:10.1046/j.1460-9568.2003.02677.x

Aller, M.I., Pecoraro, V., Paternain, A.V., Canals, S., Lerma, J., 2015. Increased Dosage of High-Affinity Kainate Receptor Gene grik4 Alters Synaptic Transmission and Reproduces Autism Spectrum Disorders Features. J Neurosci 35, 13619-13628. doi:10.1523/JNEUROSCI.2217-15.2015

Arora, V., Pecoraro, V., Aller, M.I., Román, C., Paternain, A.V., Lerma, J., 2018. Increased Grik4 Gene Dosage Causes Imbalanced Circuit Output and Human Disease-Related Behaviors. CellReports 23, 3827-3838. doi:10.1016/j.celrep.2018.05.086

Artinian, J., Peret, A., Marti, G., Epsztein, J., Crepel, V., 2011. Synaptic Kainate Receptors in Interplay with INaP Shift the Sparse Firing of Dentate Granule Cells to a Sustained Rhythmic Mode in Temporal Lobe Epilepsy 31, 10811-10818. doi:10.1523/JNEUROSCI.0388-11.2011

Artinian, J., Peret, A., Mircheva, Y., Marti, G., Crépel, V., 2015. Impaired neuronal operation through aberrant intrinsic plasticity in epilepsy. Ann Neurol. 77, 592-606. doi:10.1002/ana.24348

Barberis, A., Sachidhanandam, S., Mulle, C., 2008. GluR6/KA2 kainate receptors mediate slow-deactivating currents. 28, 6402-6406. doi:10.1523/JNEUROSCI.1204-08.2008

Beed, P.S., Salmen, B., Schmitz, D., 2009. GluK2-Mediated Excitability within the Superficial Layers of the Entorhinal Cortex. PLoS ONE 4, e5576-11. doi:10.1371/journal.pone.0005576

Bettler, B., Mulle, C., 1995. Review: neurotransmitter receptors. II. AMPA and kainate receptors. Neuropharmacology 34, 123-139. doi:10.1016/0028-3908(94)00141-e

Braga, M.F.M., Aroniadou-Anderjaska, V., Xie, J., Li, H., 2003. Bidirectional modulation of GABA release by presynaptic glutamate receptor 5 kainate receptors in the basolateral amygdala. J Neurosci 23, 442-452. doi:10.1523/JNEUROSCI.23-02-00442.2003

Bureau, I., Bischoff, S., Heinemann, S.F., Mulle, C., 1999. Kainate receptor-mediated responses in the CA1 field of wild-type and GluR6-deficient mice. J Neurosci 19, 653663. doi:10.1523/JNEUROSCI.19-02-00653.1999

Bureau, I., Dieudonne, S., Coussen, F., Mulle, C., 2000. Kainate receptor-mediated synaptic currents in cerebellar Golgi cells are not shaped by diffusion of glutamate. Proc Natl Acad Sci USA 97, 6838-6843.

Carta, M., Fievre, S., Gorlewicz, A., Mulle, C., 2014. Kainate receptors in the hippocampus. European Journal of Neuroscience 39, 1835-1844. doi:10.1111/ejn.12590

Carta, M., Opazo, P., Veran, J., Athané, A., Choquet, D., Coussen, F., Mulle, C., 2013. CaMKIIdependent phosphorylation of GluK5 mediates plasticity of kainate receptors. The EMBO Journal 32, 496-510. doi:10.1038/emboj.2012.334

Castillo, P.E., Malenka, R.C., Nicoll, R.A., 1997. Kainate receptors mediate a slow postsynaptic current in hippocampal CA3 neurons. Nature 388, 182-186. doi:10.1038/40645

Chamberlain, S.E.L., Jane, D.E., Jones, R.S.G., 2011. Pre- and post-synaptic functions of kainate receptors at glutamate and GABA synapses in the rat entorhinal cortex. Hippocampus 22, 555-576. doi:10.1002/hipo.20921 
Chamberlain, S.E.L., Sadowski, J.H.L.P., Teles-Grilo Ruivo, L.M., Atherton, L.A., Mellor, J.R., 2013. Long-term depression of synaptic kainate receptors reduces excitability by relieving inhibition of the slow afterhyperpolarization. 33, 9536-9545. doi:10.1523/JNEUROSCI.0034-13.2013

Chandra, N., Awasthi, R., Ozdogan, T., Johenning, F.W., Imbrosci, B., Morris, G., Schmitz, D., Barkai, E., 2019. A Cellular Mechanism Underlying Enhanced Capability for Complex Olfactory Discrimination Learning. eNeuro 6. doi:10.1523/ENEURO.0198-18.2019

Contractor, A., Mulle, C., Swanson, G.T., 2011. Kainate receptors coming of age: milestones of two decades of research. Trends Neurosci 34, 154-163. doi:10.1016/j.tins.2010.12.002

Contractor, A., Sailer, A.W., Darstein, M., Maron, C., Xu, J., Swanson, G.T., Heinemann, S.F., 2003. Loss of kainate receptor-mediated heterosynaptic facilitation of mossy-fiber synapses in KA2-/- mice. J Neurosci 23, 422-429. doi:10.1523/JNEUROSCI.23-0200422.2003

Contractor, A., Swanson, G., Heinemann, S.F., 2001. Kainate receptors are involved in shortand long-term plasticity at mossy fiber synapses in the hippocampus. Neuron 29, 209216. doi:10.1016/s0896-6273(01)00191-x

Copits, B.A., Swanson, G.T., 2012. Dancing partners at the synapse: auxiliary subunits that shape kainate receptor function 1-12. doi:10.1038/nrn3335

Crépel, F., 2009. Role of presynaptic kainate receptors at parallel fiber-purkinje cell synapses in induction of cerebellar LTD: interplay with climbing fiber input. J Neurophysiol 102, 965-973. doi:10.1152/jn.00269.2009

Crépel, V., Mulle, C., 2015. Physiopathology of kainate receptors in epilepsy. Curr Opin Pharmacol 20, 83-88. doi:10.1016/j.coph.2014.11.012

Cunningham, M.O., Davies, C.H., Buhl, E.H., Kopell, N., Whittington, M.A., 2003. Gamma oscillations induced by kainate receptor activation in the entorhinal cortex in vitro. J Neurosci 23, 9761-9769. doi:10.1523/JNEUROSCI.23-30-09761.2003

Cunningham, M.O., Pervouchine, D.D., Racca, C., Kopell, N.J., Davies, C.H., Jones, R.S.G., Traub, R.D., Whittington, M.A., 2006a. Neuronal metabolism governs cortical network response state. Proc Natl Acad Sci USA 103, 5597-5601. doi:10.1073/pnas.0600604103

Cunningham, M.O., Pervouchine, D.D., Racca, C., Kopell, N.J., Davies, C.H., Jones, R.S.G., Traub, R.D., Whittington, M.A., 2006b. Neuronal metabolism governs cortical network response state. Proc Natl Acad Sci USA 103, 5597-5601. doi:10.1073/pnas.0600604103

Daw, M.I., Pelkey, K.A., Chittajallu, R., McBain, C.J., 2010. Presynaptic kainate receptor activation preserves asynchronous GABA release despite the reduction in synchronous release from hippocampal cholecystokinin interneurons. J Neurosci 30, 11202-11209. doi:10.1523/JNEUROSCI.6334-09.2010

DeVries, S.H., Schwartz, E.A., 1999. Kainate receptors mediate synaptic transmission between cones and "Off" bipolar cells in a mammalian retina. Nature 397, 157-160. doi:10.1038/16462

Dolman, N.P., More, J.C.A., Alt, A., Knauss, J.L., Pentikäinen, O.T., Glasser, C.R., Bleakman, D., Mayer, M.L., Collingridge, G.L., Jane, D.E., 2007. Synthesis and Pharmacological Characterization of N 3-Substituted Willardiine Derivatives: Role of the Substituent at the 5-Position of the Uracil Ring in the Development of Highly Potent and Selective GLU K5Kainate Receptor Antagonists. J. Med. Chem. 50, 1558-1570. doi:10.1021/jm061041u Eder, M., Becker, K., Rammes, G., Schierloh, A., Azad, S.C., Zieglgänsberger, W., Dodt, H.-U., 2003. Distribution and properties of functional postsynaptic kainate receptors on 
neocortical layer V pyramidal neurons. J Neurosci 23, 6660-6670. doi:10.1523/JNEUROSCI.23-16-06660.2003

Epsztein, J., Represa, A., Jorquera, I., Ben-Ari, Y., Crépel, V., 2005. Recurrent mossy fibers establish aberrant kainate receptor-operated synapses on granule cells from epileptic rats. 25, 8229-8239. doi:10.1523/JNEUROSCI.1469-05.2005

Fernandes, H.B., Catches, J.S., Petralia, R.S., Copits, B.A., Xu, J., Russell, T.A., Swanson, G.T., Contractor, A., 2009. High-Affinity Kainate Receptor Subunits Are Necessary for lonotropic but Not Metabotropic Signaling. Neuron 63, 818-829. doi:10.1016/j.neuron.2009.08.010

Fievre, S., Carta, M., Chamma, I., Labrousse, V., Thoumine, O., Mulle, C., 2016. Molecular determinants for the strictly compartmentalized expression of kainate receptors in CA3 pyramidal cells. Nature Communications 7, 12738. doi:10.1038/ncomms 12738

Fisahn, A., Contractor, A., Traub, R.D., Buhl, E.H., Heinemann, S.F., McBain, C.J., 2004. Distinct roles for the kainate receptor subunits GluR5 and GluR6 in kainate-induced hippocampal gamma oscillations. J Neurosci 24, 9658-9668. doi:10.1523/JNEUROSCI.2973-04.2004

Frerking, M., Ohliger-Frerking, P., 2002. AMPA receptors and kainate receptors encode different features of afferent activity. J Neurosci 22, 7434-7443. doi:10.1523/JNEUROSCI.22-17-07434.2002

Goldin, M., Epsztein, J., Jorquera, I., Represa, A., Ben-Ari, Y., Crépel, V., Cossart, R., 2007. Synaptic kainate receptors tune oriens-lacunosum moleculare interneurons to operate at theta frequency. J Neurosci 27, 9560-9572. doi:10.1523/JNEUROSCI.1237-07.2007

Guzmán, Y.F., Ramsey, K., Stolz, J.R., Craig, D.W., Huentelman, M.J., Narayanan, V., Swanson, G.T., 2017. A gain-of-function mutation in the GRIK2 gene causes neurodevelopmental deficits. Neurol Genet 3, e129. doi:10.1212/NXG.0000000000000129

Hedrick, T.P., Nobis, W.P., Foote, K.M., Ishii, T., Chetkovich, D.M., Swanson, G.T., 2017. Excitatory Synaptic Input to Hilar Mossy Cells under Basal and Hyperexcitable Conditions. eNeuro 4. doi:10.1523/ENEURO.0364-17.2017

Huxter, J.R., Zinyuk, L.E., Roloff, E.V.L., Clarke, V.R.J., Dolman, N.P., More, J.C.A., Jane, D.E., Collingridge, G.L., Muller, R.U., 2007. Inhibition of kainate receptors reduces the frequency of hippocampal theta oscillations. J Neurosci 27, 2212-2223. doi:10.1523/JNEUROSCI.3954-06.2007

Jane, D.E., Lodge, D., Collingridge, G.L., 2009. Kainate receptors: pharmacology, function and therapeutic potential. Neuropharmacology 56, 90-113. doi:10.1016/j.neuropharm.2008.08.023

Jiang, L., Xu, J., Nedergaard, M., Kang, J., 2001. A kainate receptor increases the efficacy of GABAergic synapses. Neuron 30, 503-513. doi:10.1016/s0896-6273(01)00298-7

Kamiya, H., Ozawa, S., Manabe, T., 2002. Kainate receptor-dependent short-term plasticity of presynaptic Ca2+ influx at the hippocampal mossy fiber synapses. J Neurosci 22, 9237-9243. doi:10.1523/JNEUROSCI.22-21-09237.2002

Kerchner, G.A., Wang, G.D., Qiu, C.S., Huettner, J.E., Zhuo, M., 2001. Direct presynaptic regulation of GABA/glycine release by kainate receptors in the dorsal horn: an ionotropic mechanism. Neuron 32, 477-488. doi:10.1016/s0896-6273(01)00479-2

Koga, K., Liu, M.-G., Qiu, S., Song, Q., O'Den, G., Chen, T., Zhuo, M., 2015. Impaired presynaptic long-term potentiation in the anterior cingulate cortex of Fmr1 knock-out mice. 35, 2033-2043. doi:10.1523/JNEUROSCI.2644-14.2015 
Koga, K., Sim, S.-E., Chen, T., Wu, L.-J., Kaang, B.-K., Zhuo, M., 2012. Kainate receptormediated synaptic transmissions in the adult rodent insular cortex. J Neurophysiol 108, 1988-1998. doi:10.1152/jn.00453.2012

Koromina, M., Flitton, M., Blockley, A., Mellor, I.R., Knight, H.M., 2019. Damaging coding variants within kainate receptor channel genes are enriched in individuals with schizophrenia, autism and intellectual disabilities. Sci. Rep. 9, 19215-11. doi:10.1038/s41598-019-55635-4

Kron, M.M., Zhang, H., Parent, J.M., 2010. The developmental stage of dentate granule cells dictates their contribution to seizure-induced plasticity. J Neurosci 30, 2051-2059. doi:10.1523/JNEUROSCI.5655-09.2010

Lanore, F., Labrousse, V.F., Szabo, Z., Normand, E., Blanchet, C., Mulle, C., 2012. Deficits in morphofunctional maturation of hippocampal mossy fiber synapses in a mouse model of intellectual disability. 32, 17882-17893. doi:10.1523/JNEUROSCI.2049-12.2012

Lauri, S.E., Bortolotto, Z.A., Bleakman, D., Ornstein, P.L., Lodge, D., Isaac, J.T., Collingridge, G.L., 2001. A critical role of a facilitatory presynaptic kainate receptor in mossy fiber LTP. Neuron 32, 697-709. doi:10.1016/s0896-6273(01)00511-6

Lauri, S.E., Ryazantseva, M., Orav, E., Vesikansa, A., Taira, T., 2021. Kainate receptors in the developing neuronal networks. Neuropharmacology 108585.

doi:10.1016/j.neuropharm.2021.108585

Lauri, S.E., Segerstråle, M., Vesikansa, A., Maingret, F., Mulle, C., Collingridge, G.L., Isaac, J.T.R., Taira, T., 2005. Endogenous activation of kainate receptors regulates glutamate release and network activity in the developing hippocampus. J Neurosci 25, 4473-4484. doi:10.1523/JNEUROSCI.4050-04.2005

Lauri, S.E., Vesikansa, A., Segerstråle, M., Collingridge, G.L., Isaac, J.T.R., Taira, T., 2006. Functional Maturation of CA1 Synapses Involves Activity-Dependent Loss of Tonic Kainate Receptor-Mediated Inhibition of Glutamate Release. Neuron 50, 415-429. doi:10.1016/j.neuron.2006.03.020

Lerma, J., Marques, J.M., 2013. Kainate Receptors in Health and Disease 80, 292-311. doi:10.1016/j.neuron.2013.09.045

Li, H., Rogawski, M.A., 1998. GluR5 kainate receptor mediated synaptic transmission in rat basolateral amygdala in vitro. Neuropharmacology 37, 1279-1286. doi:10.1016/s00283908(98)00109-9

Li, P., Wilding, T.J., Kim, S.J., Calejesan, A.A., Huettner, J.E., Zhuo, M., 1999. Kainate-receptormediated sensory synaptic transmission in mammalian spinal cord. Nature 397, 161164. doi:10.1038/16469

Lourenço, J., Cannich, A., Carta, M., Coussen, F., Mulle, C., Marsicano, G., 2010. Synaptic activation of kainate receptors gates presynaptic $\mathrm{CB}(1)$ signaling at $\mathrm{GABAergic}$ synapses. Nat Neurosci 13, 197-204. doi:10.1038/nn.2481

Maraschi, A., Ciammola, A., Folci, A., Sassone, F., Ronzitti, G., Cappelletti, G., Silani, V., Sato, S., Hattori, N., Mazzanti, M., Chieregatti, E., Mulle, C., Passafaro, M., Sassone, J., 2019. Parkin regulates kainate receptors by interacting with the GluK2 subunit. Nature Communications 1-10. doi:10.1038/ncomms6182

Marchal, C., Mulle, C., 2004. Postnatal maturation of mossy fibre excitatory transmission in mouse CA3 pyramidal cells: a potential role for kainate receptors. J Physiol (Lond) 561, 27-37. doi:10.1113/jphysiol.2004.069922 
Marshall, J.J., Xu, J., Contractor, A., 2018. Kainate Receptors Inhibit Glutamate Release Via Mobilization of Endocannabinoids in Striatal Direct Pathway Spiny Projection Neurons. 38, 3901-3910. doi:10.1523/JNEUROSCI.1788-17.2018

Matsuda, K., Budisantoso, T., Mitakidis, N., Sugaya, Y., Miura, E., Kakegawa, W., Yamasaki, M., Konno, K., Uchigashima, M., Abe, M., Watanabe, I., Kano, M., Watanabe, M., Sakimura, K., Aricescu, A.R., Yuzaki, M., 2016. Transsynaptic Modulation of Kainate Receptor Functions by C1q-like Proteins 1-17. doi:10.1016/j.neuron.2016.04.001

Melyan, Z., Lancaster, B., Wheal, H.V., 2004. Metabotropic regulation of intrinsic excitability by synaptic activation of kainate receptors. 24, 4530-4534. doi:10.1523/JNEUROSCI.5356-03.2004

Mulle, C., Sailer, A., Pérez-Otaño, I., Dickinson-Anson, H., Castillo, P.E., Bureau, I., Maron, C., Gage, F.H., Mann, J.R., Bettler, B., Heinemann, S.F., 1998. Altered synaptic physiology and reduced susceptibility to kainate-induced seizures in GluR6-deficient mice. Nature 392, 601-605. doi:10.1038/33408

Mulle, C., Sailer, A., Swanson, G.T., Brana, C., O'Gorman, S., Bettler, B., Heinemann, S.F., 2000. Subunit composition of kainate receptors in hippocampal interneurons. Neuron 28, 475-484. doi:10.1016/s0896-6273(00)00126-4

Møllerud, S., Hansen, R.B., Pallesen, J., Temperini, P., Pasini, D., Bornholt, J., Nielsen, B., Mamedova, E., Chalupnik, P., Paternain, A.V., Lerma, J., Diaz-delCastillo, M., Andreasen, J.T., Frydenvang, K., Kastrup, J.S., Johansen, T.N., Pickering, D.S., 2019. N-(7-(1HImidazol-1-yl)-2,3-dioxo-6-(trifluoromethyl)-3,4-dihydroquinoxalin-1(2H)-yl)benzamide, a New Kainate Receptor Selective Antagonist and Analgesic: Synthesis, X-ray Crystallography, Structure-Affinity Relationships, and in Vitro and in Vivo Pharmacology. ACS Chem. Neurosci. 10, 4685-4695. doi:10.1021/acschemneuro.9b00479

Noebels, J.L., Avoli, M., Rogawski, M.A., Olsen, R.W., Delgado-Escueta, A.V., Buckmaster, P.S., 2012. Mossy Fiber Sprouting in the Dentate Gyrus, 4 ed. National Center for Biotechnology Information (US), Bethesda (MD).

Paternain, A.V., Herrera, M.T., Nieto, M.A., Lerma, J., 2000. GluR5 and GluR6 kainate receptor subunits coexist in hippocampal neurons and coassemble to form functional receptors. J Neurosci 20, 196-205. doi:10.1523/JNEUROSCI.20-01-00196.2000

Peret, A., Christie, L.A., Ouedraogo, D.W., Gorlewicz, A., Epsztein, J., Mulle, C., Crépel, V., 2014. Contribution of aberrant GluK2-containing kainate receptors to chronic seizures in temporal lobe epilepsy. CellReports 8, 347-354. doi:10.1016/j.celrep.2014.06.032

Petrovic, M.M., Viana da Silva, S., Clement, J.P., Vyklicky, L., Mulle, C., González-González, I.M., Henley, J.M., 2017. Metabotropic action of postsynaptic kainate receptors triggers hippocampal long-term potentiation. Nat Neurosci 20, 529-539. doi:10.1038/nn.4505

Pinheiro, P.S., Lanore, F., Veran, J., Artinian, J., Blanchet, C., Crépel, V., Perrais, D., Mulle, C., 2013. Selective block of postsynaptic kainate receptors reveals their function at hippocampal mossy fiber synapses. Cerebral Cortex 23, 323-331. doi:10.1093/cercor/bhs022

Pinheiro, P.S., Mulle, C., 2008. Presynaptic glutamate receptors: physiological functions and mechanisms of action. Nat Rev Neurosci 9, 423-436. doi:10.1038/nrn2379

Pinheiro, P.S., Perrais, D., Coussen, F., Barhanin, J., Bettler, B., Mann, J.R., Malva, J.O., Heinemann, S.F., Mulle, C., 2007. GluR7 is an essential subunit of presynaptic kainate autoreceptors at hippocampal mossy fiber synapses. Proc Natl Acad Sci USA 104, 1218112186. doi:10.1073/pnas.0608891104 
Regoni, M., Cattaneo, S., Mercatelli, D., Novello, S., Passoni, A., Bagnati, R., Davoli, E., Croci, L., Consalez, G.G., Albanese, F., Zanetti, L., Passafaro, M., Serratto, G.M., Fonzo, A., Valtorta, F., Ciammola, A., Taverna, S., Morari, M., Sassone, J., 2020. Pharmacological antagonism of kainate receptor rescues dysfunction and loss of dopamine neurons in a mouse model of human parkin-induced toxicity. Cell Death and Disease 1-11. doi:10.1038/s41419-020-03172-8

Represa, A., Robain, O., Tremblay, E., Ben-Ari, Y., 1989. Hippocampal plasticity in childhood epilepsy. Neurosci Lett 99, 351-355. doi:10.1016/0304-3940(89)90472-2

Rodriguez-Moreno, A., Herreras, O., Lerma, J., 1997. Kainate receptors presynaptically downregulate GABAergic inhibition in the rat hippocampus. Neuron 19, 893-901. doi:10.1016/s0896-6273(00)80970-8

Ruiz, A., Sachidhanandam, S., Utvik, J.K., Coussen, F., Mulle, C., 2005. Distinct subunits in heteromeric kainate receptors mediate ionotropic and metabotropic function at hippocampal mossy fiber synapses. 25, 11710-11718. doi:10.1523/JNEUROSCI.404105.2005

Sachidhanandam, S., Blanchet, C., Jeantet, Y., Cho, Y.H., Mulle, C., 2009. Kainate Receptors Act as Conditional Amplifiers of Spike Transmission at Hippocampal Mossy Fiber Synapses. J Neurosci 29, 5000-5008. doi:10.1523/JNEUROSCI.5807-08.2009

Schmitz, D., Mellor, J., Nicoll, R.A., 2001. Presynaptic kainate receptor mediation of frequency facilitation at hippocampal mossy fiber synapses. Science 291, 1972-1976. doi:10.1126/science.1057105

Scott, R., Lalic, T., Kullmann, D.M., Capogna, M., Rusakov, D.A., 2008a. Target-cell specificity of kainate autoreceptor and $\mathrm{Ca2+-store-dependent} \mathrm{short-term} \mathrm{plasticity} \mathrm{at} \mathrm{hippocampal}$ mossy fiber synapses. J Neurosci 28, 13139-13149. doi:10.1523/JNEUROSCI.293208.2008

Scott, R., Ruiz, A., Henneberger, C., Kullmann, D.M., Rusakov, D.A., 2008b. Analog modulation of mossy fiber transmission is uncoupled from changes in presynaptic $\mathrm{Ca} 2+$. 28, 7765-7773. doi:10.1523/JNEUROSCI.1296-08.2008

Segerstråle, M., Juuri, J., Lanore, F., Piepponen, P., Lauri, S.E., Mulle, C., Taira, T., 2010. High firing rate of neonatal hippocampal interneurons is caused by attenuation of afterhyperpolarizing potassium currents by tonically active kainate receptors. J Neurosci 30, 6507-6514. doi:10.1523/JNEUROSCI.4856-09.2010

Selak, S., Paternain, A.V., Aller, M.I., Aller, I.M., Pico, E., Rivera, R., Lerma, J., 2009. A role for SNAP25 in internalization of kainate receptors and synaptic plasticity. Neuron 63, 357371. doi:10.1016/j.neuron.2009.07.017

Shin, R.-M., Tully, K., Li, Y., Cho, J.-H., Higuchi, M., Suhara, T., Bolshakov, V.Y., 2010. Hierarchical order of coexisting pre- and postsynaptic forms of long-term potentiation at synapses in amygdala. Proc Natl Acad Sci USA 107, 19073-19078. doi:10.1073/pnas.1009803107

Stachniak, T.J., Sylwestrak, E.L., Scheiffele, P., Hall, B.J., Ghosh, A., 2019. Elfn1-Induced Constitutive Activation of mGluR7 Determines Frequency-Dependent Recruitment of Somatostatin Interneurons. J Neurosci 39, 4461-4474. doi:10.1523/JNEUROSCI.227618.2019

Straub, C., Hunt, D.L., Yamasaki, M., Kim, K.S., Watanabe, M., Castillo, P.E., Tomita, S., 2011. Distinct functions of kainate receptors in the brain are determined by the auxiliary subunit Neto1. Nat Neurosci 14, 866-873. doi:10.1038/nn.2837 
Sun, H.Y., Bartley, A.F., Dobrunz, L.E., 2009. Calcium-permeable presynaptic kainate receptors involved in excitatory short-term facilitation onto somatostatin interneurons during natural stimulus patterns. J Neurophysiol 101, 1043-1055. doi:10.1152/jn.90286.2008

Sun, H.Y., Dobrunz, L.E., 2006. Presynaptic kainate receptor activation is a novel mechanism for target cell-specific short-term facilitation at Schaffer collateral synapses. 26, 1079610807. doi:10.1523/JNEUROSCI.2746-06.2006

Sutula, T., Cascino, G., Cavazos, J., Parada, I., Ramirez, L., 1989. Mossy fiber synaptic reorganization in the epileptic human temporal lobe. Ann Neurol. 26, 321-330. doi:10.1002/ana.410260303

Sylwestrak, E.L., Ghosh, A., 2012. Elfn1 regulates target-specific release probability at CA1interneuron synapses. Science 338, 536-540. doi:10.1126/science.1222482

Tang, M., Pelkey, K.A., Ng, D., Ivakine, E., McBain, C.J., Salter, M.W., McInnes, R.R., 2011. Neto1 Is an Auxiliary Subunit of Native Synaptic Kainate Receptors 31, 10009-10018. doi:10.1523/JNEUROSCI.6617-10.2011

Valbuena, S., Lerma, J., 2016. Non-canonical Signaling, the Hidden Life of Ligand-Gated Ion Channels. Neuron 92, 316-329. doi:10.1016/j.neuron.2016.10.016

Vignes, M., Collingridge, G.L., 1997. The synaptic activation of kainate receptors. Nature 388, 179-182. doi:10.1038/40639

West, P.J., Dalpé-Charron, A., Wilcox, K.S., 2007. Differential contribution of kainate receptors to excitatory postsynaptic currents in superficial layer neurons of the rat medial entorhinal cortex. NSC 146, 1000-1012. doi:10.1016/j.neuroscience.2007.02.035

Wu, L.-J., Zhao, M.-G., Toyoda, H., Ko, S.W., Zhuo, M., 2005. Kainate receptor-mediated synaptic transmission in the adult anterior cingulate cortex. J Neurophysiol 94, 18051813. doi:10.1152/jn.00091.2005

Wyeth, M.S., Pelkey, K.A., Yuan, X., Vargish, G., Johnston, A.D., Hunt, S., Fang, C., Abebe, D., Mahadevan, V., Fisahn, A., Salter, M.W., McInnes, R.R., Chittajallu, R., McBain, C.J., 2017. Neto Auxiliary Subunits Regulate Interneuron Somatodendritic and Presynaptic Kainate Receptors to Control Network Inhibition. CellReports 20, 2156-2168. doi:10.1016/j.celrep.2017.08.017

Xu, J., Marshall, J.J., Fernandes, H.B., Nomura, T., Copits, B.A., Procissi, D., Mori, S., Wang, L., Zhu, Y., Swanson, G.T., Contractor, A., 2017. Complete Disruption of the Kainate Receptor Gene Family Results in Corticostriatal Dysfunction in Mice. CellReports 18, 1848-1857. doi:10.1016/j.celrep.2017.01.073

Yang, E.J., Harris, A.Z., Pettit, D.L., 2007. Synaptic kainate currents reset interneuron firing phase. J Physiol (Lond) 578, 259-273. doi:10.1113/jphysiol.2006.118448

Zhuo, M., 2017a. Cortical kainate receptors and behavioral anxiety 1-7. doi:10.1186/s13041017-0297-8

Zhuo, M., 2017b. Ionotropic glutamate receptors contribute to pain transmission and chronic pain. Neuropharmacology 112, 228-234.

doi:10.1016/j.neuropharm.2016.08.014 